\title{
O EFEITO DE UM TERRENO COM PROFESSORES NA TEORIA E NA FORMAÇÃO DO ETNÓGRAFO
}

\author{
Telmo H. Caria ${ }^{1}$ (2004)
}

\section{Um início focalizado}

Quando iniciei o meu trabalho de campo com professores no final de 1992 tinha algumas idéias sobre o problema teórico que me interessava estudar. No essencial queria saber que uso e que sentido é que os professores no seu contexto de trabalho davam ou podiam dar ao conhecimento abstrato que tinham tido acesso nos seus processos de educação formal.

Tinha feito uma revisão da literatura científica durante um ano e meio e ela dava-me à segurança suficiente para pensar que o problema seleccionado tinha actualidade e pertinência científicas no quadro das teorias e dos resultados empíricos que encontrei sobre a temática das identidades dos professores em associação com a temática da profissionalidade docente. O problema a tratar tinha também um interesse que estava para além da minha actividade de investigador: tinha essencialmente a ver com o facto de ser formador de professores.

Para responder a este problema fui tornando claro para mim, que a informação recolhida tinha que ser obtida nos termos formulados pelos próprios professores e não nos termos em que eu como formador já era capaz de fazer. Foi por ter claro esta opção, que decidi fazer trabalho etnográfico e decidi, no mesmo momento, que pretendia desenvolver uma estratégia de investigação que rompesse com a epistemologia de várias investigações que então surgiam em Portugal sobre os professores, a saber: o facto de se estar perante um conjuntura de reforma educativa, levava muitos investigadores a desenvolverem processos e hipóteses de investigação que acabavam sempre por evidenciar o desfasamento entre o

\footnotetext{
1 Docente de Sociologia e Ciências Sociais do Departamento de Economia, Sociologia e Gestão da Universidade de Trásos-Montes e Alto Douro e Investigador Efectivo do Centro de Investigação e Intervenção Educativas (CIIE) da Faculdade de Psicologia e Ciências da Educação da Universidade do Porto (tcaria@utad.pt). Página Web: www.home.utad.pt/ tcaria/
} 
que era politicamente enunciado para a educação e o que era contextualmente implementado pelos professores.

Este tipo de conclusões eram desenvolvidas tanto com conotações positivas como negativas para os professores, mas ambas participavam do mesmo pressuposto: a racionalidade dos professores era comparada com a racionalidade da decisão política, e vice-versa.

Comparação que me parecia desajustada. Fruto desta tomada de posição pareceu-me desde logo que a análise documental relativa à reforma educativa em curso tinha que ficar num plano secundário, não sendo por isso a primeira prioridade da investigação empírica.

A primeira conclusão que tiraria é a de que não estava às cegas nem pretendia cultivar qualquer tipo de cegueira aparente no início do meu trabalho de campo: tinha um problema que me guiava, que era passível de elaboração teórica, e tinha uma epistemologia que me situava.

Assim, tinha a convicção que através do trabalho etnográfico poderia observar e acompanhar, em concreto, o processo de trabalho pedagógico dos professores, onde poderia comparar o que era comparável: o uso contextual do conhecimento abstracto, nos termos definidos pelos próprios, em diferentes condições sociais e escolares (diferentes trajectórias sociais, gerações e sistemas de formação, disciplinas, etc) que contemplassem a heterogeneidade social e profissional dos professores.

Assim, os professores não seriam questionados a partir de problemas que lhes eram exteriores, com os quais se tinham que comparar, nem eram obrigados a enunciar sua própria racionalidade de modo discursivo e abstracto, como era típico da racionalidade política da reforma educativa. Eu iria no trabalho etnográfico estar suficientemente perto dos professores para os poder entender.

A escolha do grupo de professores a estudar foi decidida por questões de oportunidade e de familiaridade minhas com o meio (conhecimentos pessoais, facilidade de acesso, dimensão da escola e nível de escolaridade) e não por qualquer tipo de pressuposto teórico.

\section{Primeiros conflitos sócio-cognitivos}


Sem entrar no pormenor do processo de integração, negociação e adopção da minha presença pelos professores naquela escola, no início do trabalho de campo rapidamente me apercebi de dois fenômenos, contraditórios, que punham em causa a minha estratégia de investigação para poder esclarecer o problema que me guiava:

(1) o essencial do trabalho pedagógico não era feito na escola, nem não era colectivizado pelo grupo no local, daí que a minha observação de interacções entre professores nos espaços informais da escola e nas reuniões não tinham qualquer relevância para o problema;

(2) todas as tentativas que fazia para perceber o que era programado para as aulas, os materiais que eram construídos, o que era reflectido sobre as aulas e o que era avaliado a posteriori (todo o processo de trabalho), deparava com a resistência dos professores em falar sobre o assunto, porque, como rapidamente percebi, o grupo na escola não falava entre si sobre de tais temas, trata se de uma matéria do estrito foro individual e privado. Eu estava a pôr em causa algo que era interdito ao grupo.

De facto, estava a pretender que o grupo se comportasse comigo de um modo que não era o modo comum deles o fazerem entre eles.

A conclusão a que cheguei era a de que o facto de os ter abordado por via da Escola, fechava-me imediatamente as vias de acesso aos espaços domésticos de cada professor, onde o processo de trabalho pedagógico era concebido e autoavaliado.

Mesmo sem querer era o próprio grupo que me obrigava a fazer uma delimitação empírica do objecto de estudo: estudar professores, entrando pela Escola implicava não poder ter acesso aos espaços domésticos, familiares e residenciais das pessoas que eram professores.

Todas as perguntas que de alguma forma procuravam trazer o extra-escolar e o extraprofissional de cada um, passado ou presente, para dentro das conversas na Escola tinha a sua recusa educada.

A conseqüência mais óbvia era a de que a sala de aula era um tempo de trabalho que se encontrava no prolongamento do espaço individual e privado de cada professor, daí que a hipótese, que no início não tinha colocado de parte, de poder observar salas de aula teve que ser imediatamente posta de parte, mesmo antes de ser pensada a sério. 
O que me restava então do meu objecto de investigação, perguntava para mim mesmo? Como é que então eu poderia perceber o processo e a organização do trabalho pedagógico dos professores?

A questão de fundo era ainda mais grave, porque o que estava em causa não era só não ter informação sobre o processo de trabalho pedagógico dos professores, era também não ter informação sobre uma das principais pistas teóricas de explicação para lidar com a heterogeneidade social dos professores: o poder explicativo das trajectórias sociais.

Assim, fiquei limitado a histórias de vida que quase sempre começavam nas possíveis razões para a opção por um curso superior - e se ela tinha ou não sido no início equacionada com a possibilidade de ter uma carreira de professor - sendo o tempo de vida anterior, de infância, de escolaridade básica, da vida familiar com os pais e de adolescência, respondido em termos de evasivas, que não eram mais do que recusas educadas.

Considerava esta questão como grave, porque ela chocava directamente com a cultura institucional e disciplinar da Sociologia em que me tinha formado. Assim, mesmo sem pensar demoradamente no assunto, eu tinha a consciência prática de que a minha a hipótese mais forte, para poder abordar um grupo socialmente heterogêneo por via do trabalho, seria analisar os processos de reprodução de capitais e patrimônios herdados e saber o modo como estes tinham estruturado de modo diferenciado as possibilidades de se seguir uma carreira de professor.

Seriam estes modos estruturalmente diferenciados, dados pela análise das trajectórias sociais, que implicitamente admitia poderem explicar algumas das diferenças nos modos de trabalhar pedagógico e, portanto, do uso que se fazia do conhecimento abstracto. O facto de o meu orientador científico ser um antropólogo permitia-me mais facilmente lidar com este conflito latente, mas não resolvia definitivamente a questão, porque o que estava em causa era também um problema de conceptualização da investigação, que mais tarde tive que enfrentar: será que continuava a ter sentido teórico formalizar a diferenciação de modos de trabalhar pedagógico em termos de identidades profissionais?

\section{A resolução pragmática dos conflitos}


O facto de não poder ter acesso à organização do trabalho pedagógico de cada professor implicava circunscrever a investigação etnográfica aos espaços e tempos do trabalho dos professores que eram públicos (feitos à vista de todos) e que eram formais (reuniões) ou informais (convívio e conversação na sala de professores).

Face à necessidade de reformular a minha estratégia de investigação interrogava-se se não teria então que tomar por objecto a Escola, isto é, a multiplicidade de relações que os professores tinham com pais, funcionários, alunos e entidades administrativas.

Percebi mais tarde que a razão que justificava esta minha interrogação era a necessidade de ter um objecto de investigação que correspondesse a algo que se aproximasse de uma totalidade social, pelo menos como na altura a entendia.

O que seria então o contexto de trabalho do professor, que permitiria delimitaria os contornos dos fenômenos que seriam de conter como mais relevantes para responder ao problema que me guiava? Se a totalidade da vida da pessoa de cada professor não era possível considerar como totalidade enquadradora e explicativa do seu trabalho (apreendido através dos conceitos de identidade e de trajectória social como inicialmente admiti), parecia que à primeira vista a alternativa era a de considerar a totalidade da Escola-local.

O que suponha, do ponto de vista teórico, aproximar-me do conceito de cultura organizacional.

Em qualquer caso, mesmo que a totalidade social a considerar fosse a Escola-local acabaria sempre por ter privilegiado uma categoria particular de actores, os professores: eram estes que me interessavam como formador e eram estes que mais ligados poderiam estar ao problema que me guiava: o uso contextual do conhecimento abstracto. E seriam estes que mais autoridade tinham na Escola para configurarem aquilo que seria a cultura organizacional.

Desta forma, mesmo que passasse a enquadrar teoricamente a minha investigação em torno das teorias sobre as Culturas Organizacionais (e para isso comecei a ler bibliografia sobre o tema), isso não parecia ter implicações imediatas na estratégia de terreno que estava a desenvolver: acompanhar o quotidiano dos professores nos espaços públicos, formais ou informais da escola. 
Assim, decidi adiar o problema: a abordagem dos restantes actores da escola poderia ficar para um momento posterior, tal qual já tinha decidido fazer com a documentação da reforma educativa.

\section{O efeito de conjuntura}

Como disse atrás, os professores falavam pouco entre si sobre o que faziam na sala de aula e praticamente nada sabiam de essencial sobre como cada um planeava e organiza o quotidiano do trabalho pedagógico.

Mas, contrariamente ao que se poderia esperar, falavam imenso sobre o mundos que rodeavam o seu mundo: os alunos-problema, as turmas, os pais, o meio social da escola, a administração escolar, as outras escolas, as novas políticas educativas e seu impacto na Escola-local. Como rapidamente me apercebi eu estava na Escola-local num momento muito particular: as rotinas de trabalho dos professores em geral, independentemente das disciplinas, da antiguidade na profissão e dos anos escolares, eram questionados pela reforma educativa, pois os processos tradicionais e locais de avaliar e de organizar o curriculum pareciam ter que ser actualizados face à nova conjuntura.

A tradição de organizar e pensar o trabalho docente carecia de ser actualizada porque existiam duas idéias que tinham que ser apropriadas pelos professores e sobre isso havia à partida pouco consenso, a saber: (1) a idéia de que a reprovação no ensino básico, num ano lectivo que não fosse final de ciclo, passava a ser uma excepção e não uma regra para os $20 \%$ a $30 \%$ dos alunos da escola que costumavam reprovar por ano lectivo; (2) a idéia de que teria que passar a haver uma actividade interdisciplinar, com valor curricular, realizada nos espaços e tempos das disciplinas.

Em conclusão, a conjuntura fazia os professores falarem da sua tradição local de trabalho e confrontarem-se entre si sobre o modo de a actualizarem, lidando ao mesmo tempo com a heterogeneidade social e a diversidade de experiências dos professores.

A conjuntura obrigava os professores a saírem do seu mundo social naturalizado, a explicitarem muitos dos saberes implícitos da profissão - que noutras circunstâncias permaneceriam no silêncio - a tornarem a realidade educativa inteligível pelo seu relato partilhado em interacção 
Negociar e consensualizar significados e linguagens antes naturalizados, adaptar as rotinas a novas circunstâncias e relembrar normas de conduta que excluíam adaptações e significados antes não falados, eram os fenômenos mais comuns que observava, em que participava e em que falava com os professores.

Esta situação fez-me questionar o modo como concebia a análise de uma totalidade social, pois contrariamente ao que pressuponha, no mundo singular dos professores estava contido uma multiplicidade de outros mundos: os outros, que para o grupo havia que reavaliar, dada a actualização da tradição local que estava em curso.

$\mathrm{O}$ mundo dos professores sem deixar de ser etnocêntrico não podia deixar de ignorar o outro, dada a relação de poder em que estavam envolvidos e investidos pela reforma educativa. Como fui percebendo, a pouco e pouco, era o modo como se conceptualizava cultura que estava em causa: a cultura neste caso não seria um padrão de conduta, um sistema de relações intergrupos, uma estrutura ou uma invariância práticosimbólica, passava a ser uma dinâmica interactiva comum, um processo de fabricação da realidade partilhada, uma micro-história, que não se confundia com as problematizações em torno das identidades, geralmente demasiado individualistas e demasiado referenciadas a contextos macro sociais. As contribuições da fenomenologia e mais particularmente da etnometodologia para o conceito de cultura eram incontornáveis. Mais interessante ainda, o conceito de cultura que esboçava organizava um sentido suposto nas condutas do grupo que se concretizava na procura em explicar a mudança, - e não, como era tradicional na investigação em Ciências Sociais, na procura de explicar a ordem - ainda que o nosso objecto não estivesse centrado nos conflitos sociais.

O conceito de cultura que formalizei, na sequência deste esboço de problematização que o terreno obrigou, veio a resolver os problemas que acima enunciei acima e que havia adiado: tinha uma definição de contexto de trabalho dos professores e tinha uma delimitação do objecto de investigação que me permitia fazer a "economia da informação" sobre as trajectórias sociais, das identidades profissionais e dos "mundos dos outros" na visão dos professores. Tinha finalmente, a segurança de que ia perceber o trabalho dos professores, na esfera pública, formal e informal, do grupo a partir da reflexividade que estes interactivamente desenvolviam. 
Estava em condições de garantir que ia perceber os professores nos seus próprios termos, respondendo ao meu interesse de formador. Tinha encontrado o meu objecto teórico-empírico de investigação. 